\title{
Evaluation of biosecurity practices in a laying hens farm using Biocheck.UGent
}

\author{
Nadir Alloui ${ }^{a}$, Sassia Sellaouia ${ }^{a}$, Amar Ayachi ${ }^{a}$, Omar Bennoune ${ }^{a}$ \\ aLaboratory of Environment, Health and Animal Production, University of Batna, Algeria.
}

ABSTRACT The Biocheck.UGent scoring system was developed to measure and quantify the level of biosecurity in animal husbandry. This tool is composed of all the relevant elements of biosecurity in poultry farms (broilers and laying hens) and is subdivided into external and internal biosecurity. The peculiarity of this scoring system is that it takes into account the relative importance of the different aspects of biosecurity, resulting in a risk-weighted score. The biosecurity scores obtained are provided immediately after completing the questionnaire and the scores for each sub-category can be compared to global averages to allow the poultry farmer to compare the results obtained and correct any anomalies that are on their farm. In Algeria, preliminary results from a survey in poultry houses of 30.000 laying hens show a wide range of biosecurity levels on that farm, with internal biosecurity scores ranging from 6 to $72 \%$ and external biosecurity scores ranging from 28 to 92\% in the subgroups. The overall scores were $50 \%$ and $54 \%$, respectively. These early results show that despite the well-known importance of biosecurity, there is a lack of implementation of many biosecurity measures.

KEYWORDS: poultry diseases; poultry farmers; veterinary prophylaxis.

Accepted May 28, $2021 \quad$ Published online July 29, 2021

Cite this article: Alloui et al. (2021) Evaluation of biosecurity practices in a laying hens farm using Biocheck.UGent. Multidisciplinary Science Journal 3: e20210014, doi:10.29327/multiscience.2021014.

\section{Introduction}

Poultry farming is the most important animal production in Algeria (Benfrid and Ferrah 1988). The latter has contributed to the development of protein production, thanks to the marketing of white meats and eggs. (Alloui and Bennoune 2013). It is characterized by highly diversified production and marketing systems, made up of a few large integrated companies and a large number of small poultry farmers (Mahmoudi et al 2015). There are also medium-sized producers who rely heavily on large integrated farms to supply breeding stock and feed (Kaci 2014). The Algerian poultry industry produces an average of 340,000 tons of white meat and over 4.8 billion eggs annually. It consists of 20,000 farmers employing around 500,000 people (Kaci and Cheriet 2013).

Between 2000 and 2012, Batna region was the country's leading producer of table eggs (DSA 2015). However, this animal sector is faced with many problems such as increasing the price of raw materials (corn, soybeans) and the frequent appearance of infectious diseases (Alloui and Ayachi 2012; Barberis et al. al 2018). The spread of these diseases may be due to poor biosecurity. This requires further investigation to determine the causes and risk factors that cause the frequent occurrence of these diseases (Al Saffar et al 2006).

In Algeria, a health charter for breeding practices is applied, drawn up by the Ministry of Agriculture. This charter was designed to harmonize the different stages of raising chickens, layers, turkeys, and other species of poultry. All 
biosecurity measures are indicated and they concern feed safety and good hygiene practices on poultry farms (MADR 2012).

The absence or minimal presence of disease greatly contributes to the safety of animal source feeds from farms, indicating the paramount importance of biosecurity. Poor biosecurity means the exposure of poultry flocks to various infectious diseases, which can lead to great economic losses (Gelaude et al 2014). Regular monitoring and evaluation of the compliance of various biosecurity measures on farms is essential to avoid health disasters. Most of the tools used for biosecurity assessment are developed in the form of checklists (Dewulf et al 2018). As qualitative methods, they simply indicate whether a particular biosecurity measure is applied or whether it is present or not. This type of descriptive assessment is useful, but a quantitative method would be very practical and of greater value. When the level of biosecurity is quantified, specific areas such as hygiene and sanitation can be identified and improved easily.

The objective of this study is to evaluate the biosecurity practices in the breeding of laying hens. The Biocheck.UGent scoring system was used to measure and quantify the level of biosecurity on the farm where the poultry is located. This first study will allow us to obtain an analysis of the methods used by the poultry farmer in the laying hens farm in the Batna region in Algeria.

\section{Material and Methods}

A farm of 30.000 laying hens was subjected to the biosecurity survey in the Wilaya of Batna in Algeria during the year 2019. The farm was visited for geolocation and to obtain consent to conduct the survey. Immediately after the consent, interviews with staff were conducted collaborating with veterinary practitioners from the region. This farm is made up of 6 farm buildings with mechanical ventilation. Each building has a capacity of 5.000 hens raised in batteries. Feeding and watering are automated. The breed or strain of poultry raised on this farm is Tetra SL (Tetra SL-LL-Country 2020).

All the environmental factors (temperature, humidity, light, and ventilation) are controlled using a control cabinet located at the store level of each building.

\section{Quantitative study of biosecurity}

The "Biocheck.UGent" scoring system was used to assess biosafety. It includes 79 dichotomous or trichotomous questions, which are divided into several sub-categories for external and internal biosecurity. Each sub-category consists of 2 to 19 questions. The answer to each question gives a score between zero (when this measure is not implemented at all) and one (when the measure is fully implemented). Depending on the importance of a particular biosecurity measure, the score per question is multiplied by a weighting factor (Laanen et al 2013; Gelaude et al 2014). The final score for internal and external biosecurity can range from zero, indicating a complete absence of the biosecurity measures described, to 100 , indicating the full application of the measures described.

The questionnaire can be consulted on the website: http://www.Biocheck.UGent.be

\section{Statistic study}

Averages of scores were obtained for quantitative external biosecurity variables (purchase of pullets, transport of eggs, supply of feed and water, disposal of manure and corpses, entry of visitors and staff, supply of materials, infrastructure and biological vectors, and location of the farm) and internal biosecurity (disease management, cleaning, disinfection, equipment, and measures between compartments and egg management). The overall biosecurity scores in the various sub-categories were compared to the world average using the "Biocheck.UGent" test for a population average. Global averages were taken from all layer farms, which can be found on the "Biocheck.UGent" guide.

\section{Results and discussion}

As described below in Table 1 and Figure 1, the biosecurity scoring system is subdivided into two categories (external and internal biosecurity) and ten sub-categories. Initially, the content and relative importance of each of these sub-categories is evaluated by a score (\%). 
In our survey, the overall biosecurity score of the farm is estimated at $54 \%$, which is equal to that of the world average. On average, the external biosafety score (54\%) was higher than the internal biosafety score (45\%) during this first biosafety audit (Table 1). In the external biosecurity category, the following three subcategories had the lowest average scores: depopulation and transport of hens (28\%), removal of manure and corpses (44\%), and movement of hens visitors and agricultural workers (35\%). In the sub-categories of external biosecurity, infrastructure and biological vectors $(62 \%)$, supply of equipment $(60 \%)$, and transport of eggs $(92 \%)$, were obtained the highest scores. The other remaining sub-categories obtained mean scores varying between 49 and 55\%; these are the purchase of laying hens, the supply of drinking water, and the location of the farm. The score for the purchase of the day-old chick was not investigated. Regarding internal biosecurity, egg management (72\%) and cleaning and disinfection (62\%) obtained the highest score, while disease management (40\%) and that of materials and measures between compartments (6\%), obtained the lowest score. The farm's overall external biosecurity score is equal to that of the average global biosecurity ( $55 \%$ vs. $55 \%$ ); however, that of the farm's internal biosecurity is low (45\% vs. $62 \%$ ). The total overall result of the biosecurity score of the farm studied is relatively close to the world average ( $50 \%$ vs. $58 \%$ ).

Table 1 Results of farm biosecurity scores after completing the questionnaire.

\begin{tabular}{lcc}
\hline External Biosecurity & Farm average & World average \\
\hline A. Purchase of day-old chicks & S.O. & $44 \%$ \\
B. Purchase of laying hens & $55 \%$ & $67 \%$ \\
C. Depopulation and transport of chickens & $28 \%$ & $51 \%$ \\
D. Egg transport & $92 \%$ & $39 \%$ \\
E. feed and water & $49 \%$ & $47 \%$ \\
F. Removal of manure and corpses & $44 \%$ & $43 \%$ \\
G. Visitors and agricultural workers & $35 \%$ & $64 \%$ \\
H. Supply of equipment & $60 \%$ & $70 \%$ \\
I. Infrastructure and biological vectors & $62 \%$ & $65 \%$ \\
J. Location of farm & $55 \%$ & $59 \%$ \\
Sub-total - External biosecurity & $54 \%$ & $54 \%$ \\
\hline Internal Biosecurity & & \\
\hline K. Disease management & $40 \%$ & $68 \%$ \\
L. Cleaning and disinfection & $62 \%$ & $63 \%$ \\
M. Materials and measurments between compartiments & $6 \%$ & $57 \%$ \\
N. Egg managment & $72 \%$ & $54 \%$ \\
Sub-total-Internal biosecurity & $45 \%$ & $62 \%$ \\
\hline Total & $\mathbf{5 0 \%}$ & $\mathbf{5 8 \%}$ \\
\hline
\end{tabular}

The implementation of additional biosecurity measures based on advice given to poultry and farmers could lead to an overall improvement in biosecurity scores (Guernat 2000). This preliminary study, in Algeria, demonstrates the need to carry out large-scale surveys on a higher number of poultry farms to determine an average of the national score and establish comparisons with the scores observed by authors (Conan et al 2013; Dorea et al 2010). It should be clarified that the maximum scores (100\%) should be our end goal, not the average scores. The study attempted to develop a risk-based quantitative tool to measure the level of biosecurity in a laying hen farm in a standardized and reproducible manner. The Biocheck.UGent scoring system allows us for the first time to quantify biosecurity at the flock level of laying hens, taking into account all relevant aspects of biosecurity. Different livestock farms can easily be compared to each other, and each farm can be tracked over time when the same scoring system is used (Amass et al 2006; Berndtson et al 1996; Boklund et al 2004; Tanquilut et al 2020). If the biosecurity scoring system is used nationwide, the level of biosecurity could be mapped and areas at high risk for disease spread identified. This can be useful in the case of epizootics and makes it possible to monitor the sites hosting the animals.

Benchmarking results on farms has already been shown to increase farmers' awareness and prompt them to improve the current situation of their farms (Tablante 2008; van Libergen et al 2018). Figure 1 presents our results in 
the form of a graph against the average values. The larger the blue area, the better score. The designation of the axes corresponds to the letters corresponding to the parameters found in table 1.

EXTERNAL BIOSECURITY

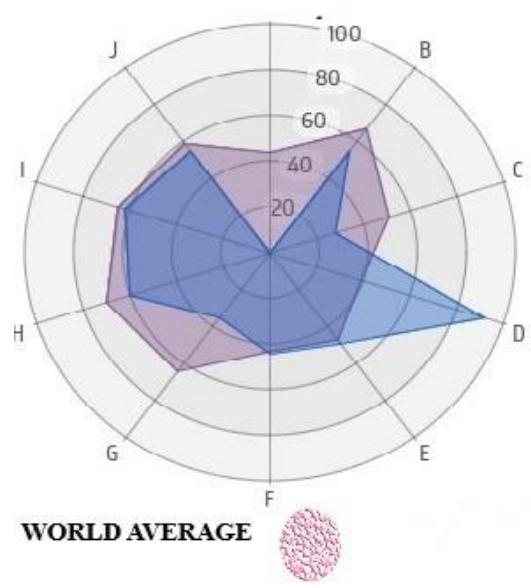

INTERNAL BIOSECURITY

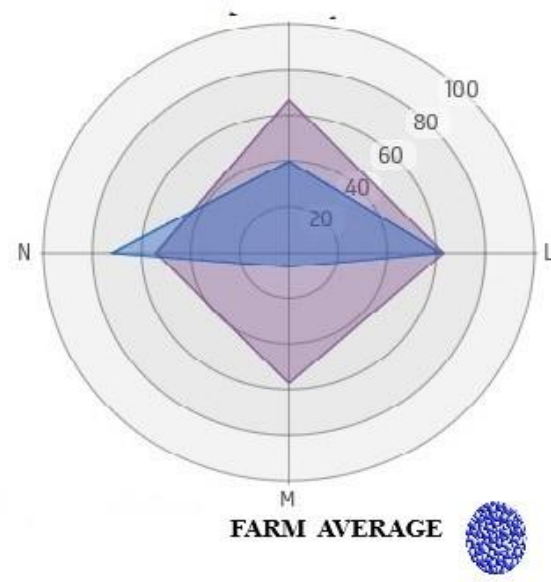

Figure 1 Graphical results of farm biosecurity scores provided by BiocheckUGent

\section{Conclusions}

The biosecurity measures applied in the laying hen farm located in Batna region (Algeria) are insufficient. Corrective action should be taken to improve internal and external biosecurity scores. It is desirable to take a higher sample of poultry farms to have a national score on biosecurity.

\section{Conflict of Interest}

The authors declare no conflict of interest.

\section{Acknowledgments}

We thank the owner of the farm for helping us to carry out this survey, as well as the veterinarian in charge of the health monitoring of the poultry flock. Thanks also to the Biocheck.UGent team for the data analysis.

\section{References}

Alexander DJ (2007) An overview of the epidemiology of avian influenza. Vaccine 25:5637-5644.

Alloui N, Bennoune O (2013) Poultry production in Algeria: Current situation and future prospects. World's Poultry Science Journal 69:601-612. DOI: 10.1017/S0043933913000615

Alloui N, Ayachi A (2012) Biosecurity practices in Algerian poultry farms. Online Journal of Animal and Feed Research 2:80-83.

Al-Saffar A, Al-Nasser A, Al-Haddad A, Al-Bahouh M, and Mashaly M (2006) Principles of Poultry Biosecurity Program. Kuwait Institute for Scientific Research, Safat, Kuwait.

Amass SF, Baysinger A (2006) Swine disease transmission and prevention. In: Straw BE, Zimmerman JJ, Allaire SD, Taylor DJ (ed) Diseases of Swine, 9th ed. Blackwell Publishing Ltd., Oxford, UK, pp 1075-1098.

Barberis A, Boudaoud A, Gorrill A, Loupias J, Ghram A, Lachheb J, Alloui N, Ducatez MF (2020) Full-length genome sequences of the first H9N2 avian influenza viruses isolated in the Northeast of Algeria. Virology journal 17:108. DOI: 10.1186/s12985-020-01377-z

Benfrid M, Ferrah A (1988) Les productions animals en Algerie : faible elasticite des productions classiques et emergence de l'aviculture industrielle. Cahiers du CERAD, 2 eme trimestre 71-102.

Berndtson E, Emanuelson U, Engvall A, Danielsson-Tham L (1996) A 1-year epidemiological study of Campylobacter in Swedish chicken farms. Preventive Veterinary Medicine 26:167-185. 
Boklund A, Alban L, Mortensen S, Houe H (2004) Biosecurity in 116 Danish fattening swine herds: descriptive results and factors analysis. Preventive Veterinary Medicine 66:49-62.

Conan A, Goutard FL, Khiev R, Ponsich A, Tarantola A, Sornd S, Vong S (2013) A community-based education trial to improve backyard poultry biosecurity in rural Cambodia. Acta Tropica 125:294-302. DOI: 10.1016/j.actatropica.2012.12.006

Dewulf J, Immerseel FV, Luyckx K, Postma M, Vabeselaere B (2018) How to measure biosecurity and the hygiene status of farms. In: Dewulf J, Immerseel, FV (ed) Biosecurity in Animal Production and Veterinary Medicine: From Principles to Practice. Uitgeverij Acco, Blijde Ink-omststraat, 22. Belgie, Leuven, pp 117-300.

Direction des services agricoles (DSA) de Batna (2015) Bilan de la production agricole de la wilaya de Batna, Algérie.

Dorea FC, Berghaus R, Hofacre C, Cole DJ (2010) Survey of biosecurity protocols and practices adopted by growers on commercial poultry farms in Georgia, USA. Avian Diseases 54:1007-1015. DOI: 10.1637/9233-011210-Reg.1.

Gelaude P, Dewulf J, Laanen M, Schlepers M, Verlinden M (2014) Biocheck.UGent: a quantitative tool to measure biosecurity at broiler farms and the relationship with technical performances and antimicrobial use. Poultry Science 93:1-12. DOI: 10.3382/ps.201404002

Gernat A (2000) Poultry farm biosecurity. Ed. College of Agricultural. N.C. State University.

Kaci A (2014) Les déterminants de la compétitivité des entreprises avicoles algériennes. Thèse Doctorat, ENSA, El Harrach, Algérie.

Kaci A, Cheriet $F$ (2013) Analyse de la compétitivité de la filière de viande de volaille en Algérie: tentatives d'explication d'une déstructuration chronique. New Mediterranean 12:11-21.

Laanen MB, Callens J, Dewulf E, de Jong D, Maes M, Persoons S, Ribbens M, Strubbe M (2013) Relationship between biosecurity and production/antimicrobial treatment characteristics in pig herds. Veterinary Journal 198:508-512.

Mahmoudi N, Yakhlef H, Thewis A (2015) Caractérisation technico-socioprofessionnelle des exploitations avicoles en zone steppique (wilaya de M'sila, Algérie). Cahiers Agricultures 24:161-9.

Ministère de l'Agriculture et du Développement Rural (MADR) (2012) Avant-projet d'une charte de qualité et pacte de croissance encadrant et engageant les activités des professionnels de la filière avicole pour la structuration et la modernisation de l'aviculture nationale. Disponible en: www.minagri.dz/pdf/Divers/Charte. Consulté le: 12 de septembre 2019.

Tablante N (2008) Biosecurity: A vital key to poultry disease prevention. Poultry Perspectives 8:2-4

Tanquilut NC, Espaldon MVO, Eslava DF, Ancog RC, Medina CDR, Paraso RD, Domingo MGV, Dewulf J (2020) Quantitative assessment of biosecurity in broiler farms using Biocheck.UGent in Central Luzon, Philippines. Poultry Science 99:3047-3059. DOI: 10.1016/j.psj.2020.02.004

Tetra SL-LL-Country (2020) Guide d'élevage des poules pondeuses commerciales. Disponible en: http://www.babolnatetra.com/wpcontent/uploads/2019/12/tetra-sl-fr.pdf,visite. Consulté le: 26 Janvier 2021.

Van Limbergen T, Dewulf J, Klinkenberg M R, Ducatelle P, Gelaude P, Mendez J, Heinola K, Papasolomontos S, Szeleszczuk S, Maes D (2018) Scoring biosecurity in European conventional broiler production. Poultry Science: 97:74-83. 